\title{
Safety, tolerability and pharmacokinetic characterisation of DACRA KBP-042 in healthy male subjects
}

\author{
Kim Henriksen ${ }^{1}$, Karen Broekhuizen ${ }^{2}$, Wadim de Boon ${ }^{2}$, Morten Karsdal ${ }^{1}$, Asger Bihlet ${ }^{3}$, \\ Claus Christiansen ${ }^{1}$, Marlous Dillingh² ${ }^{2}$ Marieke de Kam², Raj Kumar ${ }^{4}$, Jacobus \\ Burggraaf $^{2}$, and Ingrid Kamerling ${ }^{5}$ \\ ${ }^{1}$ Nordic Bioscience \\ ${ }^{2}$ Centre for Human Drug Research \\ ${ }^{3}$ Nordic Bioscience A/S \\ ${ }^{4}$ KeyBioscience AG \\ ${ }^{5} \mathrm{CHDR}$
}

February 13, 2021

\begin{abstract}
There is a need for anti-diabetic agents successfully targeting insulin sensitivity and treating obesity control at the same time. The aim of this first-in-human study was 1) to evaluate safety and tolerability; 2) to evaluate pharmacokinetics and 3) to assess indications of receptor engagement of single ascending doses of KBP-042, a Dual Amylin and Calcitonin Receptor Agonists (DACRA) that has shown promising preclinical data, with superior activity in terms of typical amylin-induced responses including reduction of food intake, weight loss and gluco-regulatory capacities. A randomised double-blind placebo-controlled single ascending dose study was performed with six dose levels of KBP-042 (5, 7.5, 10, 20, 20 evening and 40 $\mathrm{gg})$ in healthy male adults. KBP-042 or placebo was administered as a single dose after an overnight fast, followed by a standardized lunch after four hours. KBP-042 was associated with dose-dependent complaints of nausea and vomiting, with a lack of tolerability at doses of $20 \mu \mathrm{g}$ and above. Doses of 5 to $40 \mu \mathrm{g}$ KBP-042 were behaved according to a linear pharmacokinetic profile. Indications of target receptor engagement were observed at the level of glucose control and lowering of bone resorption, compared to placebo. The results of this study showed that doses up to $40 \mu \mathrm{g}$ were safe, although tolerability was not present at the highest doses. The study confirmed target receptor engagement at the studied doses.
\end{abstract}

\section{Hosted file}

KBP-042 FIM paper Final Feb2020.pdf available at https://authorea.com/users/395519/articles/ 508758-safety-tolerability-and-pharmacokinetic-characterisation-of-dacra-kbp-042-inhealthy-male-subjects 


\section{Planned}

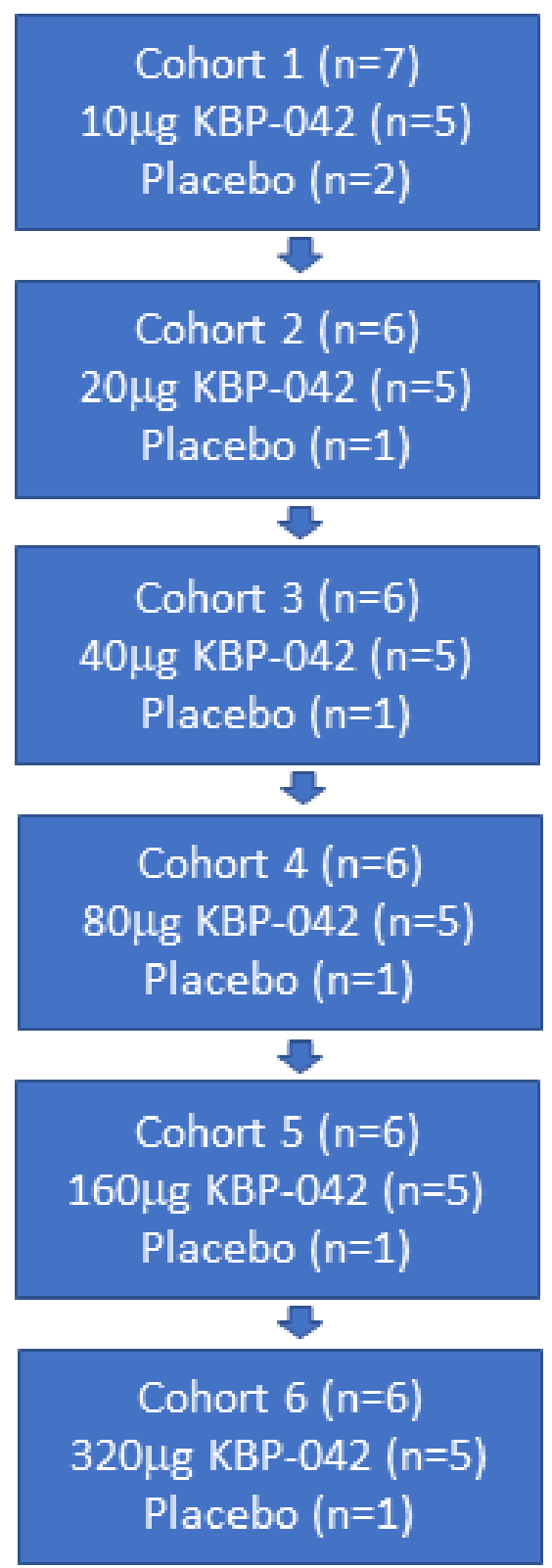

Actual
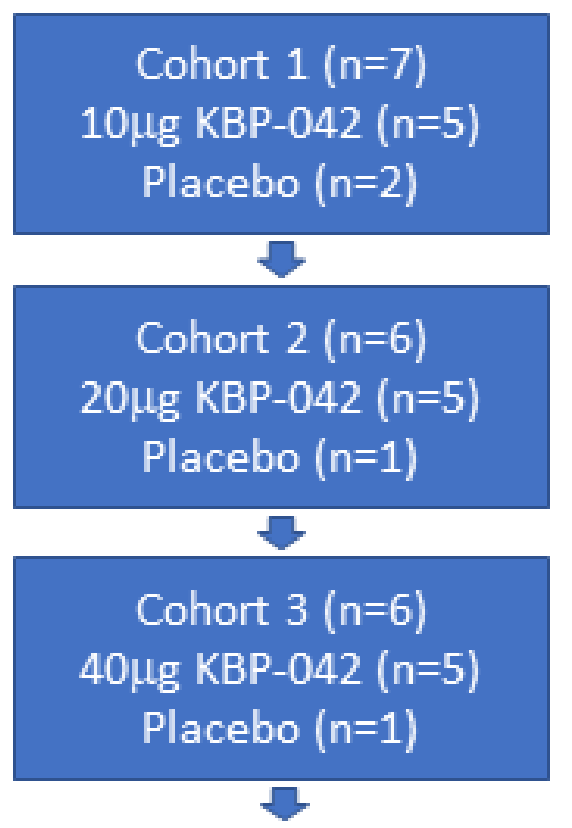

Cohort 4 ( $n=6)$ Evening

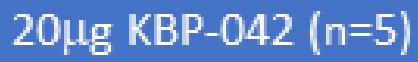
Placebo $(n=1)$

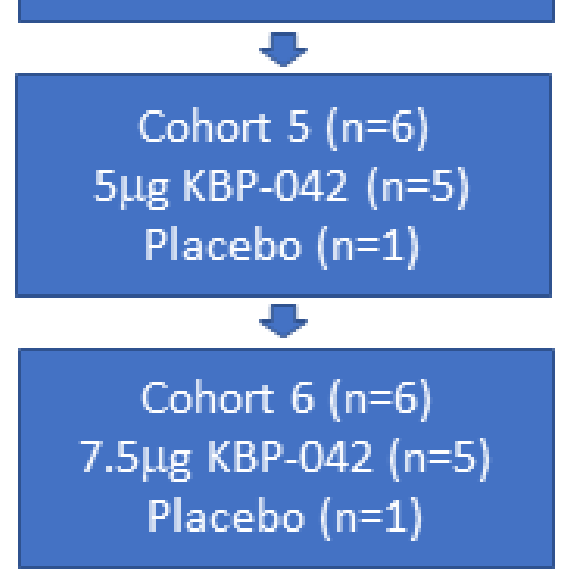



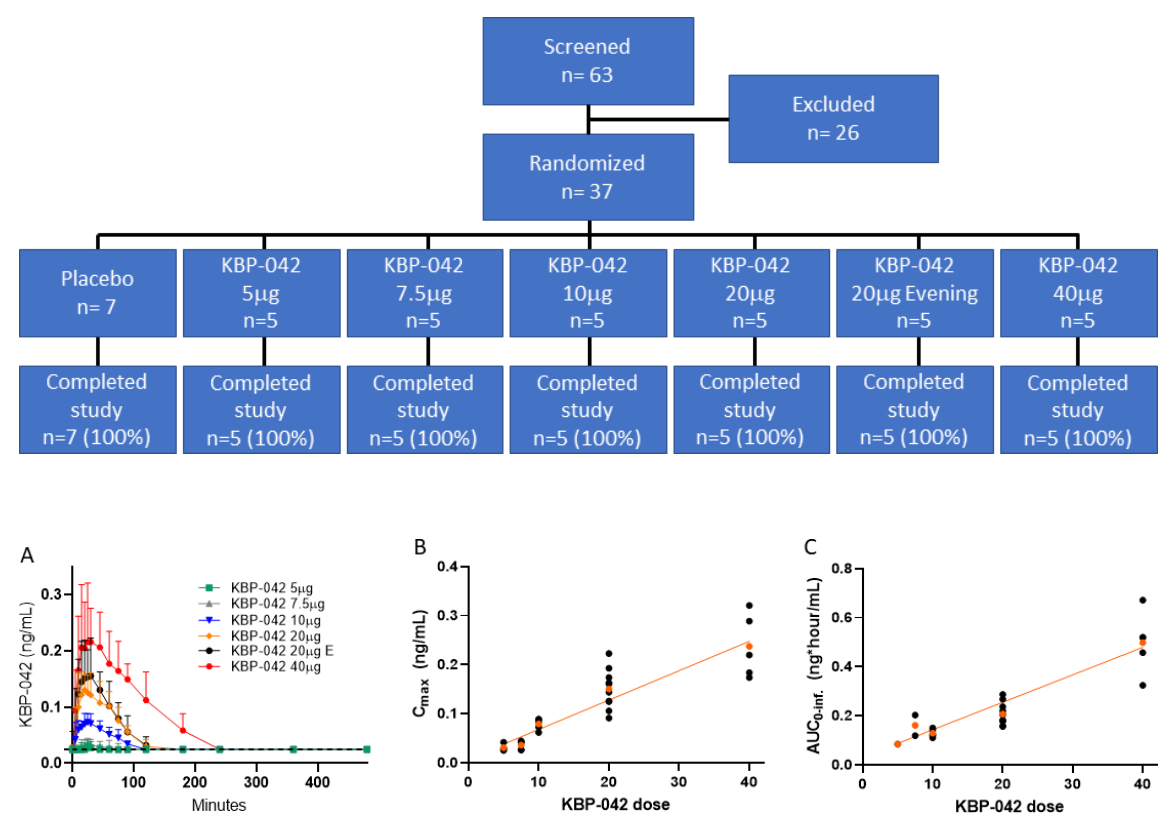

A

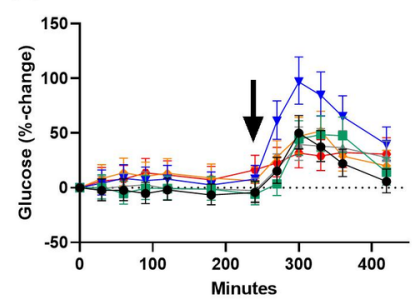

C

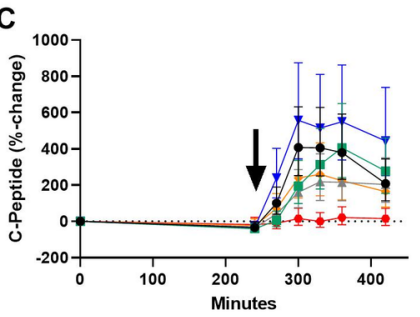

B

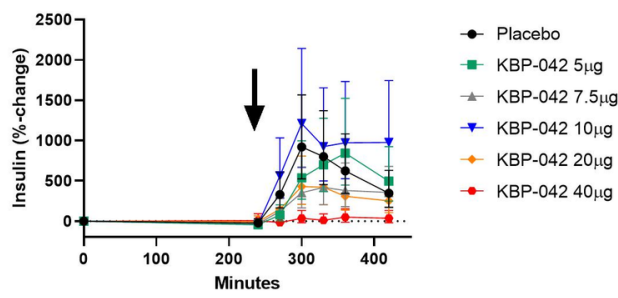

D

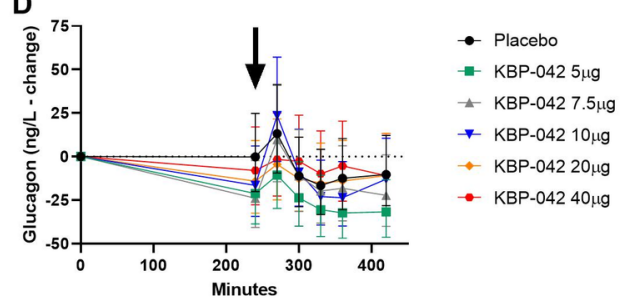


A

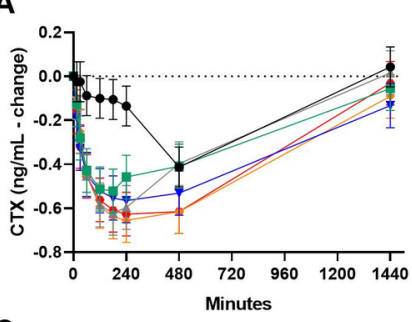

C

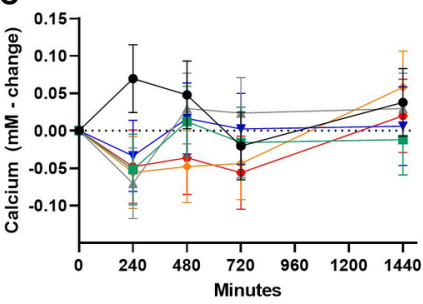

B

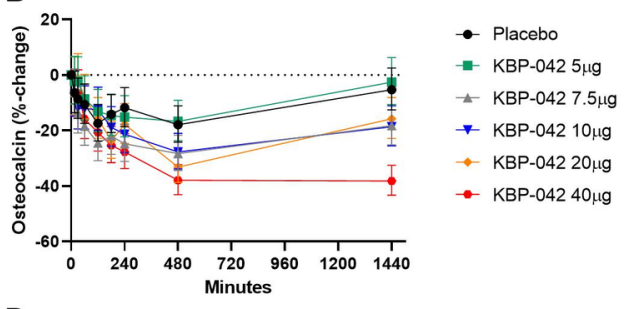

D

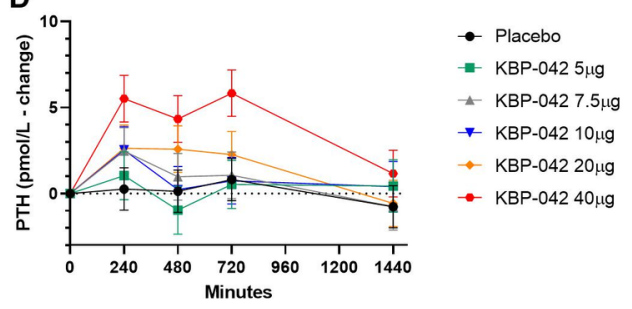

